\title{
Saber cultural e a matemática escolar: encontro necessário na educação escolar indígena
}

\section{Cultural knowledge and school mathematics: necessary meeting in indigenous school education}

\author{
Luzia Voltolini ${ }^{1}$ \\ Carmen Teresa Kaiber ${ }^{2}$
}

\begin{abstract}
Resumo
Apresentam-se, nesse artigo, resultados e análises de uma investigação que está sendo produzida na Terra Indígena Serra da Moça, no Estado de Roraima, Brasil e tem por objetivo investigar possibilidades de constituição de um currículo de Matemática para os anos finais do Ensino Fundamental, o qual considere necessidades, interesses e aspectos da cultura dos povos indígenas. Metodologicamente a investigação se insere em uma perspectiva qualitativa seguindo os pressupostos da pesquisa etnográfica, envolvendo quarenta e seis membros das comunidades da Terra Indígena Serra da Moça. Destacam-se, aqui, dados e análises referentes à percepção dos participantes sobre os conhecimentos matemáticos tradicionais que circulam na comunidade e as demandas por novos conhecimentos, necessários no contexto contemporâneo. Resultados apontam que os saberes e práticas tradicionais são úteis e atendem às necessidades do cotidiano da comunidade, entretanto há a necessidade de que novos conhecimentos sejam adquiridos.
\end{abstract}

Palavras-chave: Educação Escolar Indígena; Educação Matemática; Ensino e Aprendizagem; Currículo de Matemática.

\begin{abstract}
In this article, we present results and analyzes of an investigation being carried out in the Serra da Moça Indigenous Land in the State of Roraima, Brazil, and aims to investigate possibilities for the constitution of a Mathematics curriculum for the final years of Elementary Education, which considers needs, interests and aspects of the culture of indigenous peoples. Methodologically, the research is inserted in a qualitative perspective following the presuppositions of the ethnographic research, involving forty-six members of the communities of the Serra da Moça Indigenous Land. Data and analysis concerning the participants' perception of the traditional mathematical knowledge circulating in the community and the demands for new knowledge required in the contemporary context are highlighted here. Results show that traditional

\footnotetext{
${ }^{1}$ Doutoranda do Programa de Pós-Graduação em Ensino de Ciências e Matemática - PPGECIM, da Universidade Luterana do Brasil - ULBRA - Canoas/RS. Professora da Secretaria de Educação e Desportos do Estado de Roraima - SEED/RR e da Universidade Estadual de Roraima - UERR, Brasil. Email: luvoltolini@hotmail.com

${ }^{2}$ Doutora em Ciências da Educação pela Universidade Pontifícia de Salamanca - Espanha. Atualmente é professora titular do curso de Matemática e do Programa de Pós-Graduação em Ensino de Ciências e Matemática - PPGECIM - Universidade Luterana do Brasil - ULBRA - Canoas/RS, Brasil. Email: kaiber@ulbra.br
} 
knowledge and practices are useful and meet the daily needs of the community, however there is a need for new knowledge to be acquired.

Keywords: Indigenous School Education; Mathematical Education; Teaching and Learning; Mathematics Curriculum.

\section{Introdução}

Os povos indígenas brasileiros são detentores de uma intensa riqueza cultural que se expressa em diversas atividades (Brasil, 2005) de onde emergem saberes e práticas que circulam nas suas comunidades, o que pôde ser constatado em investigação realizada em uma comunidade indígena, a Comunidade Indígena Serra da Moça. A investigação buscou identificar os conhecimentos matemáticos produzidos e estabelecidos no local e as demandas de novos conhecimentos frente aos desafios que se apresentam no cotidiano dos povos envolvidos, sendo apresentada em Voltolini (2011).

Os resultados dessa investigação evidenciaram a existência de saberes culturais que são valorizados e praticados para satisfazer as necessidades internas da comunidade, contudo não fazem parte do currículo escolar, apesar do manifestado desejo dos membros da comunidade de reconhecimento dos mesmos. Foi possível constatar, também, que é indispensável que novos conhecimentos sejam desenvolvidos, uma vez que a interação entre indígenas e não indígenas exige conhecimentos matemáticos que vão além dos tradicionalmente utilizados, considerando as intensas relações sociais e comerciais que se estabelecem entre os membros das comunidades e a população não indígena.

As reflexões que permearam o trabalho realizado apontaram para o importante papel que a Educação Matemática tem na Educação Escolar Indígena, pois é necessário, por um lado, garantir a especificidade dessa modalidade de educação escolar e, por outro, promover possibilidades para a aquisição de conhecimentos essenciais no contexto vivenciado atualmente pelos povos indígenas. Assim, foi possível perceber a importância de realizar estudos com o intuito de investigar aspectos do contexto educativo formal das comunidades indígenas, o que motivou novos trabalhos de investigação.

Nesse contexto está sendo desenvolvido um estudo ${ }^{4}$ que tem como objetivo investigar possibilidades de constituição de um currículo de Matemática para os anos finais do Ensino Fundamental, no âmbito da Educação Escolar Indígena do Estado de Roraima, o qual articule os aspectos culturais e os saberes emergentes das ações na

\footnotetext{
${ }^{3}$ Pesquisa autorizada pelo Tuxaua e membros da Comunidade Serra da Moça, participantes da investigação. ${ }^{4}$ Doutorado em andamento. Pesquisa autorizada pela Fundação Nacional do Índio (FUNAI) sob $\mathrm{n}^{\mathbf{o}}$ 117/AAEP/PRES/2015, conforme Ofício $n^{\circ}$ 393/2015/PRES/FUNAI-MJ do Processo $n^{\circ}$ 08620.0534443/2014-11. Projeto aprovado pelo Comitê de Ética em Pesquisa (CEP) decorrente do Parecer Consubstanciado $\mathrm{n}^{\circ}$ 1.175.033 de 06/08/2015, com o número CAAE 38483414.1.0000.5349.
} 
comunidade às necessidades e interesses dos povos indígenas atendendo, também, às determinações legais. Metodologicamente, o estudo insere-se em uma perspectiva qualitativa seguindo os pressupostos da pesquisa etnográfica e busca respaldo teórico nos constructos da Etnomatemática (D’Ambrósio, 1998, 2001, 2005, 2009, 2011), da Educação Matemática Crítica (Skovsmose, 2007, 2011) e da Socioepistemologia (Cantoral, 2013, 2016). Pondera-se que os aportes teóricos tomados como referência tem potencial para dar suporte a uma proposta pedagógica para a Educação Escolar Indígena, pois têm como foco a compreensão, a valorização sociocultural e formação cidadã.

Assim, nesse artigo, apresentam-se aspectos da trajetória dos trabalhos que têm sido realizados na Terra Indígena (TI) Serra da Moça com destaque para aspectos da investigação que está em andamento, mas que já tem a coleta de dados concluída e que foi desenvolvida junto a membros das comunidades, Tuxauas ${ }^{5}$, gestores escolares, professores de Matemática da Escola Estadual Indígena (E.E.I) Adolfo Ramiro Levi ${ }^{6}$, estudantes da mesma escola, bem como seus pais e mães, os quais, voluntariamente, responderam a questionários e entrevistas sobre questões envolvendo o ensino e aprendizagem da Matemática na mencionada escola. Os dados foram coletados entre os meses de outubro de 2015 e junho de 2016, na TI Serra da Moça no Estado de Roraima. A investigação está sendo conduzida em uma perspectiva qualitativa, seguindo os pressupostos da pesquisa etnográfica em educação.

No que segue, discute-se aspectos da Educação Escolar Indígena, já no âmbito dos aportes teóricos tomados como referência, seguidos das questões metodológicas, análise e discussão de resultados.

\section{Por uma educação matemática para a educação escolar indígena}

A Educação Escolar Indígena refere-se ao conhecimento adquirido pelos povos indígenas nos processos escolares, após o contato com a sociedade não indígena (Luciano, 2006), tendo sido assegurada pela Constituição Federal de 1988 e pela Lei de Diretrizes e Bases da Educação Nacional (LDB) n 9.394/96. Embora a legislação brasileira garanta a esses povos o direito a processos escolares próprios, ainda não foram criadas condições para que os mesmos aconteçam efetivamente com o reconhecimento à sua especificidade, interculturalidade e bilinguismo/multilinguismo (Brasil, 2005).

A necessidade de assegurar escolarização de acordo com os interesses e respeito aos modos e ritmos de vida introduzem, nas escolas indígenas, um novo conceito de

\footnotetext{
5 Tuxaua é o representante da comunidade.

${ }^{6}$ Em Voltolini (2011) consta a denominação E.E.I. Índio Ajuricaba, porém foi alterada para E.E.I. Adolfo Ramiro Levi por meio do Decreto ${ }^{\circ}$ 17.632-E de 25 de setembro de 2014.
} 
educação escolar à medida que esta deve ter por objetivo, também, promover a valorização e o fortalecimento sociocultural dos povos indígenas e apropriação dos conhecimentos da sociedade não indígena, não só úteis para a melhoria de suas condições de vida, mas que venham contribuir para a formação de sujeitos com consciência de cidadania.

É reconhecido que as culturas indígenas, com seus saberes, apresentam uma Matemática rica, variada e a expressam de forma natural, valorizando contextos locais. Nesse contexto, encontra-se na Etnomatemática (D’Ambrosio, 2005) um programa de pesquisa que possibilita conhecer, interpretar e analisar possíveis manifestações matemáticas presentes nessas culturas, contribuindo, no âmbito da Matemática escolar, para delinear estratégias da ação pedagógica, de modo que essa ação não fique restrita a uma estrutura formal, mas considere todos os aspectos que envolvem os sujeitos em questão.

Segundo D’Ambrosio (2001, p. 8), a Etnomatemática tem a característica de abordar formas distintas de conhecer e de adotar uma nova postura de fazer educação, substituindo o "[...] já desgastado ensino-aprendizagem, baseado numa relação obsoleta de causa-efeito". De acordo com o autor, aprender Matemática é mais que dominar técnicas, habilidades e memorizar explicações e teorias, sendo que "[...] a aprendizagem por excelência é a capacidade de explicar, de apreender, de compreender e de enfrentar, criticamente, situações novas" (D’Ambrosio, 2001, p. 10), tornando o estudante apto a perceber que a Matemática vai além do que está prescrito no currículo desenvolvido na escola.

Monteiro \& Pompeu Jr. manifestam que a abordagem da Etnomatemática no ensino da Matemática permite "[...] uma compreensão crítica da realidade, ou, mais do que isso, permite ao aluno optar pela forma de resolver suas questões na medida em que não impõe o saber institucionalizado ao saber do senso comum, mas apenas problematiza e compara [...]" (2001, p. 66), possibilitando que o estudante reconheça que seus conhecimentos são valiosos. Entretanto, de acordo com os autores, a aquisição de novos conhecimentos pode agregar novos saberes que serão úteis para resolver as questões pessoais e comunitárias.

Conforme o documento Referencial Curricular Nacional para as Escolas Indígenas (RCNEI) para os povos indígenas, aprender Matemática “[...] é fundamental, porque permite um melhor entendimento do 'mundo dos brancos' e ajuda na elaboração de projetos comunitários que promovam a conquista da auto-sustentação das comunidades" (Brasil, 2005, p. 159). Nesse contexto, entende-se que a Matemática, nas escolas indígenas, deve contribuir para que os estudantes tenham acesso aos conhecimentos matemáticos ditos universais, considerando, porém, a valorização e 
ressignificação de conhecimentos já estabelecidos. Concorda-se, assim, com o RCNEI quando aponta que o estudo da Matemática deve ser significativo para os estudantes, favorecendo o entendimento do "[...] mundo local e também o mais amplo[...]" (Brasil, 2005, p. 160), o que destaca a sua relevância.

Nesta perspectiva, entende-se que, além da Etnomatemática, a Educação Matemática Crítica (EMC) (Skovsmose, 2007) tem muito a contribuir para que a Educação Matemática nas escolas indígenas satisfaça as necessidades destacadas. Skovsmose (2007) pondera que o ambiente escolar se constitui em um espaço de formação cidadã, de modo que a educação escolar deve ser orientada para, de forma crítica, debater questões que afetam os estudantes, não se restringindo a práticas matemáticas padronizadas como corretas, mas valorizando toda forma de conhecimento, considerando todos os aspectos que envolvem o sujeito aprendiz.

Araújo avalia que a Matemática presente nos currículos escolares da Educação Básica, quando embasada pela EMC “[...] procura problematizar a Matemática na sociedade, em geral, e nas escolas, como instituições pertencentes a essa sociedade [...]" promovendo a criticidade "[...] dos alunos/cidadãos na sociedade, discutindo questões políticas, econômicas, ambientais, dentre outras, nas quais a matemática é utilizada como suporte tecnológico" (Araújo, p. 2007, p. 21), deixando de ter como característica principal o desenvolvimento de habilidades de cálculos matemáticos realizados mecanicamente.

Nessa perspectiva, concorda-se com Skovsmose (2011) quando aponta que a Matemática presente no currículo escolar deve priorizar a aquisição de conhecimentos matemáticos necessários para que o estudante possa sair da condição de sujeito dominado para tornar-se ativo nas suas ações. Essas questões estão diretamente relacionadas com a Educação Escolar Indígena, pois ainda permanecem as marcas de submissão e exclusão adquiridas no percurso histórico, em que os indígenas tiveram que assimilar os conhecimentos de outras culturas, participando de uma educação alheia às suas necessidades (Freire, 2004).

Porém, encontra-se nos constructos da Socioepistemologia (Cantoral, 2013) o aporte que, articulado com igual força tanto ao ideário da Etnomatemática como ao da Educação Matemática Crítica, apresenta elementos os quais se julga pertinentes de serem constituintes das bases filosófica, epistemológica e pedagógica de um projeto para a Educação Matemática no âmbito da Educação Escolar Indígena.

Cantoral (2013) orienta que a Socioepistemologia, enquanto teoria, tem como objetivo compreender a construção social do conhecimento e sua difusão institucional. Suas bases foram instituídas na necessidade de explorar formas de pensamento 
matemático em ambientes escolares e não escolares e que sejam, efetivamente, usadas pela população, podendo ser propagado socialmente.

Cervantes Reyes \& Reyes-Gasperini (2016) destacam que conceber o conhecimento matemático sob o ponto de vista socioepistemológico permite considerar o seu uso e a sua funcionalidade e, dessa maneira, é fundamental que no ambiente escolar os professores e os estudantes desenvolvam atitudes ativas para que a aprendizagem seja construída, indo além das abstrações, a fim de que os conhecimentos possam ser aplicados, sendo capazes de relacionar o saber matemático como um conhecimento posto em uso.

No entanto, Cantoral, Montiel \& Reyes-Gasperini (2015) manifestam que, tradicionalmente, a organização das ações educacionais acontece por meio de uma sequência lógica de conteúdos e procedimentos, o que evidencia, segundo Cantoral (2013), que a Educação Matemática tradicional tem se estruturado em um triângulo didático que considera três polos básicos, sendo "[...] o conteúdo a ser ensinado (saber), o sujeito que aprende (aluno) e quem ensina (professor) [...]" (Cantoral, 2013, p. 45, tradução das autoras).

No triângulo didático destacado em Cantoral (2013), o ambiente sociocultural do estudante se apresenta como um meio controlado, de pouca relevância. Porém, Cantoral, Montiel \& Reyes-Gasperini afirmam que para atender a complexidade do conhecimento matemático e do funcionamento cognitivo do aluno em nível educacional, epistemológico e social, deve-se considerar as práticas sociais existentes no entorno do aprendiz, abrangendo as "[...] questões profundas como a sua cultura, seus conhecimentos, seus saberes, sua história, seu presente e a própria história que permitiu a emergência dos saberes matemáticos" (2015, p. 11, tradução das autoras).

Nessa perspectiva, a Socioepistemologia propõe a ampliação do triângulo didático tradicional, sugerindo um novo triângulo denominado Triângulo Socioepistemológico. De acordo com Cantoral (2013), o Triângulo Socioepistemológico reflete a sociedade do conhecimento, sendo constituído pelo saber, entendido como conhecimento em uso, o sujeito que pode ser representado individual ou coletivamente e o ambiente, sendo o seu ambiente de vida, que é representado pelos cenários socioculturais.

A proposta apresentada pelo autor reconhece que a Matemática está presente, também, em ambientes sociais e culturais específicos que devem ser levados em conta no momento de organizar as ações pedagógicas. Esses ambientes exigem "[...] enfoques alternativos que partam da realidade de quem aprende e dos contextos do ensino" (Cantoral, 2016, p.7, tradução das autoras). Nessa perspectiva, entende-se que a Socioepistemologia trata as questões sociais e culturais como base para a aquisição e sistematização do conhecimento matemático, explorando formas de pensamento 
matemático que circulam dentro e fora da sala de aula e são usadas de maneira eficaz pela população.

Neste sentido, pondera-se que, embora as propostas educacionais orientem sobre a necessidade da formação integral do estudante, o que se percebe é que o currículo de Matemática instituído nas escolas, particularmente nas escolas que atendem comunidades indígenas, ainda não se atém para as especificidades dos estudantes e desconsidera as suas práticas cotidianas. Ao não considerar tais práticas, as quais D’Ambrosio (2005) entende como saberes e fazeres, há um comprometimento do processo educacional, tanto em relação ao atendimento das necessidades e expectativas dos povos indígenas, quanto aos aspectos legais.

Busca-se, portanto, no contexto aqui apresentado e apoiado nos constructos da Etnomatemática, da Educação Matemática Crítica e da Socioepistemologia, apresentar aspectos dos resultados da investigação que está em andamento, cuja coleta de dados foi realizada entre os anos de 2015 e 2016, os quais se considera que podem ser tomados como referência para a constituição de um currículo de Matemática nas escolas indígenas do Estado de Roraima. Destaca-se, ainda, que resultados da investigação realizada por Voltolini (2011), os quais encaminharam o trabalho que agora está sendo realizado, serão também apresentados quando considerados pertinentes.

No que segue são apresentados os aspectos metodológicos, os quais subsidiaram e encaminharam a investigação que está em andamento.

\section{Aspectos metodológicos}

Buscando articular elementos que permitam atingir o objetivo de investigar possibilidades de constituição de um currículo de Matemática para os anos finais do Ensino Fundamental, no âmbito da Educação Escolar Indígena do Estado de Roraima, o qual considere os aspectos culturais e os saberes emergentes das ações na comunidade às necessidades e interesses dos povos indígenas atendendo, também, as determinações legais, foram estabelecidos um conjunto de objetivos específicos, procedimentos e instrumentos de investigação.

Metodologicamente, a investigação se inseriu em uma perspectiva qualitativa seguindo os pressupostos da pesquisa etnográfica. André (2004, p. 41) destaca que a pesquisa etnográfica em educação tem como preocupação central o processo educativo e "[...] se caracteriza fundamentalmente por um contato direto do pesquisador com a situação pesquisada [...]". Nesse contexto, a pesquisa de campo teve início em outubro de 2015, a partir da imersão da pesquisadora na comunidade, prolongando-se até o mês de julho de 2016. 
Assim, buscando identificar aspectos dos conhecimentos matemáticos produzidos e utilizados na TI Serra da Moça, bem como a Matemática presente no currículo e desenvolvida nos anos finais do Ensino Fundamental na E.E.I. Adolfo Ramiro Levi, foram utilizados diferentes instrumentos de coleta de dados como a observação participante, devidamente registrada em diário de campo, registros fotográficos, gravações em áudio, análise de documentos, entrevistas semiestruturadas previamente agendadas com membros da escola e das comunidades e questionários para os estudantes.

A investigação esteve concentrada na TI Serra da Moça no Estado de Roraima, onde estão localizadas as comunidades indígenas Serra da Moça, Serra do Truaru e Morcego, reconhecidas e demarcadas. Os dados foram obtidos a partir da participação voluntária de 46 sujeitos, sendo três Tuxauas, líderes das comunidades destacadas, três gestores escolares (Comunidades Serra da Moça e Truaru), três professores de Matemática da E.E.I. Adolfo Ramiro Levi, oito pais e mães de alunos, identificados como responsáveis, e 29 estudantes dos anos finais do Ensino Fundamental da E.E.I. Adolfo Ramiro Levi, localizada na Comunidade Serra da Moça.

Os participantes contribuíram expondo seus saberes, vivências e, principalmente, manifestando a sua percepção em relação à educação escolar, revelando aspectos da Educação Matemática praticada na escola e suas expectativas sobre o trabalho com a Matemática. Ao longo do texto, os participantes, ao serem mencionados, serão identificados por letras maiúsculas do alfabeto, (T) Tuxauas, (G) gestores, (P) professores, $(\mathrm{R})$ responsáveis e (E) estudantes, seguidas de um numeral que os distinga.

Optou-se por centralizar a investigação com os estudantes da E.E.I. Adolfo Ramiro Levi pelo fato de que essa escola é única na TI Serra da Moça que oferece o Ensino Médio atendendo estudantes das distintas comunidades, das fazendas e dos assentamentos localizados nas proximidades que buscam lá estudar para, posteriormente, darem continuidade aos seus estudos no Ensino Médio, embora também haja uma escola na Comunidade Truaru que oferece os anos finais do Ensino Fundamental.

No que segue, apresentam-se as comunidades indígenas Serra da Moça, Serra do Truaru e Morcego e a E.E.I. Adolfo Ramiro, ambientes onde a investigação se concentrou para, em seguida, destacar aspectos educacionais manifestados pelos sujeitos participantes. 


\section{A Escola Estadual Adolfo Ramiro Levi e as comunidades da Terra Indígena Serra da Moça}

A Comunidade Indígena Serra da Moça está localizada no Estado de Roraima, na TI Serra da Moça, região Murupu e é constituída por aproximadamente 265 pessoas $^{7}$, distribuídas em 75 famílias, predominando a existência de dois povos indígenas, Wapixana e Macuxi, com maioria Wapixana (Voltolini, 2011) que convivem de forma harmônica e respeitosa, sendo liderados por um Tuxaua e um vice-Tuxaua.

Distante $55 \mathrm{~km}$ de Boa Vista, capital do Estado, a comunidade mantém intensa relação com a sociedade não indígena, o que faz com que parte dos mitos, lendas e costumes sejam abandonados ou substituídos. No entanto, há conhecimentos tradicionais que resistem e permanecem presentes no seu cotidiano. A subsistência da comunidade está amparada na produção de alimentos básicos, destinados à alimentação das famílias e a comercialização na feira do produtor em Boa Vista, complementando a renda financeira das famílias produtoras. $\mathrm{O}$ cultivo dos produtos agrícolas é realizado, na sua maioria, por meio de técnicas tradicionais, o que possibilita a disseminação e valorização da cultura e da tradição.

Todavia, os saberes e procedimentos tradicionais produzidos e utilizados no cotidiano da comunidade podem não atender satisfatoriamente as suas demandas, pois, atualmente, a comunidade se depara com novas necessidades provenientes, em grande parte, do contato permanente e as relações estabelecidas com outras sociedades, indígenas e não indígenas, como por exemplo, as relações comerciais.

Nesse contexto, a educação escolar deve assumir uma dupla responsabilidade, garantir a valorização e o fortalecimento dos saberes tradicionais e promover a aquisição de novos conhecimentos. Essa educação está a cargo de duas escolas: a Escola Municipal Indígena (E.M.I) Vovô Jandico da Silva, que atende as crianças da Educação Infantil e dos anos iniciais do Ensino Fundamental, $1^{\circ}$ ao $3^{\circ}$ ano, e a E.E.I Adolfo Ramiro Levi onde são ofertados os demais anos do Ensino Fundamental, Ensino Médio e Educação de Jovens e Adultos (EJA). Em 2016 ${ }^{8}$, a E.E. I. Adolfo Ramiro Levi atendia estudantes das comunidades indígenas Serra da Moça, Serra do Truaru e Morcego, pertencentes à mesma Terra Indígena, além de estudantes moradores em fazendas e assentamentos próximos, por ser a única escola da região que oferece, além do Ensino Fundamental, o Ensino Médio e a EJA.

Apesar de a E.E.I. Adolfo Ramiro Levi não ter o seu Projeto Político Pedagógico (PPP) aprovado, o mesmo está em discussão e sendo construído coletivamente entre os

\footnotetext{
${ }^{7}$ Registro do Posto de Saúde no mês de janeiro de 2016.

${ }^{8}$ Informações coletas para a Tese de Doutorado em andamento.
} 
membros da escola e da comunidade. Na sua versão preliminar já se encontra registrada a missão da escola que é de orientar e preparar os estudantes para a continuidade dos estudos, para o trabalho e para a vida em sociedade, além de propor meios de valorizar e fortalecer as raízes socioculturais dos povos envolvidos, de maneira que as ações escolares sejam compreendidas como estratégias que encaminham para a conquista da autonomia ao capacitar o estudante para interpretar, analisar e utilizar seus conhecimentos em situações cotidianas nos diversos ambientes que transitam.

Assim, entende-se que os conhecimentos matemáticos produzidos e que circulam na comunidade devem ser tomados como referência na constituição do currículo, pois agregam significados às propostas de ensino, rompendo os paradigmas de verdade absoluta em que a Matemática se situa.

A Comunidade Indígena Serra do Truaru está localizada a $5 \mathrm{~km}$ da sede da Comunidade Serra da Moça, é o centro regional da Região Murupu e conta com a liderança de um Tuxaua e de um vice-Tuxaua, sendo constituída atualmente por 224 pessoas, a maioria pertencente ao povo indígena Wapixana. Na comunidade existem duas escolas, uma que atende a Educação Infantil e os anos iniciais do Ensino Fundamental e outra que atende os anos finais do Ensino Fundamental. Os estudantes do Ensino Médio estudam na E.E.I. Adolfo Ramiro Levi na Comunidade Serra da Moça.

Já a Comunidade Indígena Morcego está localizada a, aproximadamente, $10 \mathrm{~km}$ da Comunidade Serra da Moça e, atualmente, sua população é de 176 pessoas, pertencentes a 38 famílias, a maioria da etnia Macuxi, sendo que esse número é alterado com frequência devido à forma itinerante que vivem. A escola municipal local atende 56 alunos da Educação Infantil e dos anos iniciais do Ensino Fundamental e é a única unidade escolar existente na comunidade.

Assim como na Comunidade Serra da Moça, nas Comunidades Serra do Truaru e Morcego, as famílias se dedicam à agricultura, produzindo para o consumo e comercializando o excedente.

No que segue, apresentam-se percepções, conhecimentos e demandas emergentes das investigações realizadas na TI Serra da Moça analisadas à luz das teorias postas em destaque, as quais, entende-se, podem também ser tomadas como referência para a constituição do currículo de Matemática nas escolas indígenas de Roraima.

\section{Os conhecimentos presentes nas comunidades e as demandas na educação escolar}

A investigação realizada na Comunidade Indígena Serra da Moça e apresentada em Voltolini (2011) colocou em evidência que a comunidade possuía e utilizava 
conhecimentos matemáticos específicos nas suas atividades cotidianas, bem como, tinha opiniões formadas sobre o ensino da Matemática na escola, posicionando-se em relação às demandas educacionais.

Na época, em entrevista, a Sra. A. declarou: "a escola deve mostrar a realidade para que o aluno possa estudar e se ocupar com algum cargo". Na sua declaração, essa mãe aponta para a importância da educação escolar para a ascensão social dos estudantes.

Já os agricultores entrevistados manifestaram que os conhecimentos tradicionais são frequentemente usados e são úteis nas suas atividades cotidianas, todavia a Matemática ensinada na escola não é agregada às suas práticas:

$\mathrm{Na}$ roça a gente faz uso da vara [...]. No plantio de tomate a gente calcula mais ou menos meio metro entre covas e um metro entre ruas, aí vai jogando a enxada e cavando o buraco, a distância a gente calcula olhando, uma pode ficar maior que a outra mas não tem problema (Sr. A.). A gente usa Matemática prá calcular o valor do serviço, o que vai gastar. O que dá prejuízo a gente tira, o que dá lucro mantém (Sr. S.). A escola ensina muita teoria, aqui na roça precisamos da prática (Sr. F).

A vara mencionada é um instrumento utilizado tradicionalmente para demarcar o terreno, definindo onde os agricultores cultivam suas roças sendo apresentada na Figura 1.

Figura 1: Vara usada para medir terreno

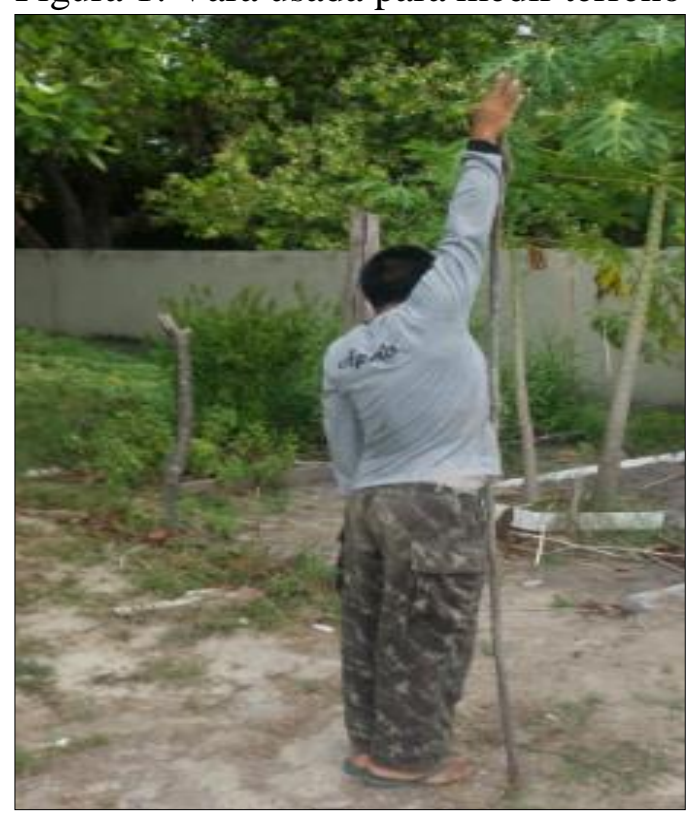

Fonte: Voltolini (2011).

O agricultor define o comprimento da vara apoiando um galho de árvore no chão, próximo aos seus pés e levantando-o até a ponta do dedo médio, com o braço esticado e 
o corpo colocado em posição vertical. Essa é a medida padrão para a demarcação. Cada vara tem, por estimativa, dois metros de comprimento, medida identificada como braça.

De posse da vara, o agricultor mede os quatro lados do terreno, obtendo-se assim a linha. Uma linha comporta 25 vezes a medida de uma vara, ou seja, supostamente o terreno que forma a linha tem 50 metros de cada lado perfazendo, assim, 2.500 metros quadrados, conforme ilustrado na Figura 2.

Figura 2: Representação da linha de roça

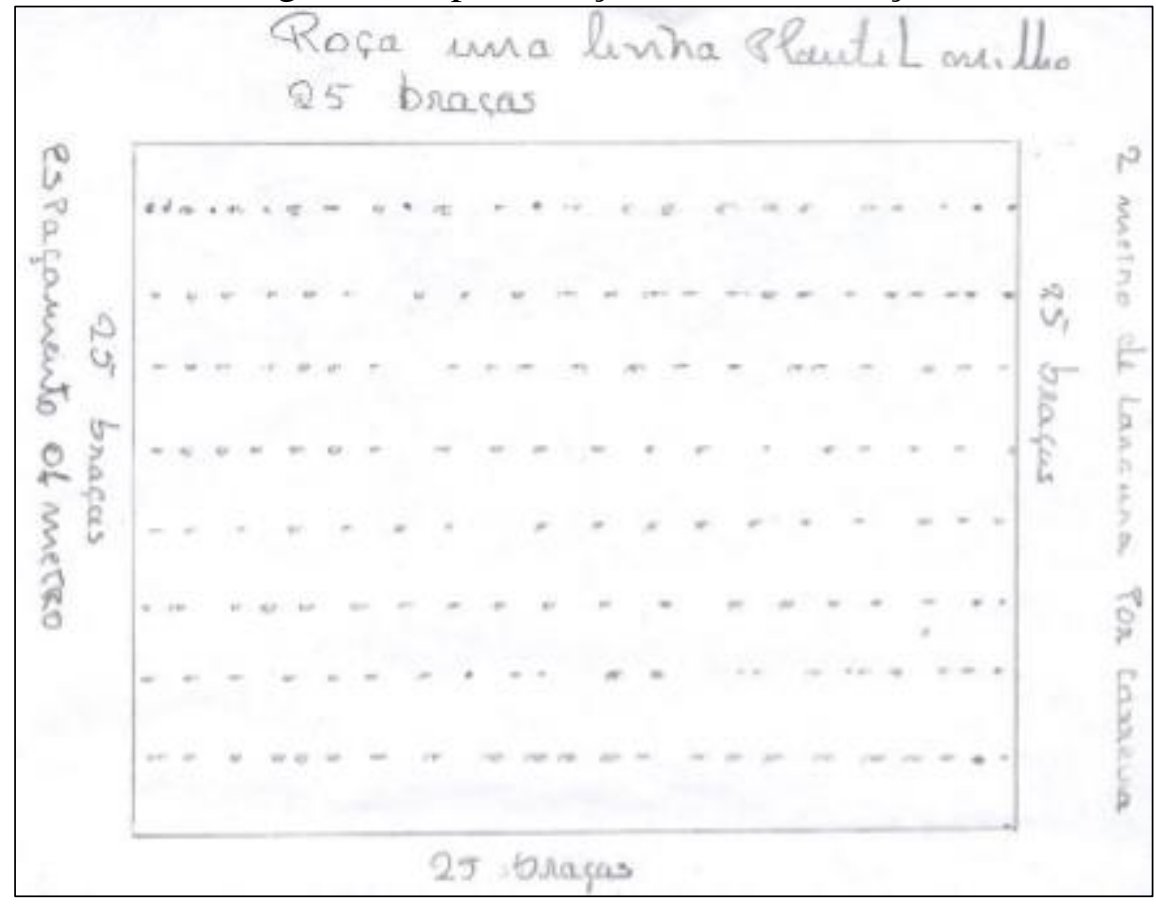

Fonte: Voltolini (2011).

Foi possível constatar, a partir das declarações dos agricultores e no esquema apresentado na Figura 2, que os mesmos reconhecem e se utilizam do conhecimento matemático tradicional e do formal. Porém, a educação escolar prioriza o ensino teórico não estabelecendo relações entre o que é ensinado e aprendido na escola com o que utilizam em suas atividades diárias.

As manifestações dos agricultores sobre o ensino da Matemática na escola corroboram com Cantoral, Reyes-Gasperini \& Montiel quando destacam que:

No sistema educacional, sabe-se que a maneira de abordar a matemática ocorre ao se concentrar em objetos matemáticos, entidades abstratas que são exemplificadas e exercitadas; evitando no tratamento didático a construção do conhecimento matemático por parte do aluno, ou seja, é concebido que a matemática lida com objetos abstratos, 
antes da praxis social e, portanto, externa ao indivíduo, sendo o professor que comunica verdades preexistentes a seus alunos [...] $(2014$, p. 108, grifo dos autores, tradução das autoras).

Tal como apontado pelos autores a abordagem da Matemática nas escolas indígenas de Roraima também é orientada por um currículo centrado em concepções alheias à realidade dos povos indígenas, conforme evidenciado nas declarações dos participantes da investigação realizada em 2015/2016. O R1 observou: "sem conhecimento a gente não é reconhecido, então eu acredito que a função da escola é esclarecer. Ensinar as matérias complicadas, mas também ensinar da nossa cultura, por exemplo, da representação das nossas pinturas. Isso tem valor”. Para o E5 e o E9, a contextualização dos conhecimentos tradicionais com o conhecimento formal poderia contribuir para a aprendizagem, conforme apresentado: "eu acho que seria mais fácil de aprender se a gente estudasse coisas da tradição junto com as contas" (E5); "é preciso aproveitar as coisas que nossos pais sabem fazer, minha mãe sabe fazer farinha e meu pai sabe fazer peneira" (E9) e o P3 acrescentou: "é preciso trazer o nosso conhecimento para dentro do currículo. O currículo hoje só traz da cultura do não índio”.

Nota-se que os participantes consideram ser relevante para os estudantes a valorização e fortalecimento da sua cultura, sendo função da escola mediar os conhecimentos tradicionais e científicos no processo de escolarização. Portanto, é fundamental reconhecer que os saberes "construídos e utilizados nas atividades desenvolvidas no cotidiano da comunidade têm grande potencial para integrar o currículo de Matemática da escola, podendo ser abordados e articulados aos conhecimentos matemáticos institucionalizados" (Voltolini \& Kaiber, 2015, p. 9).

Nesse mesmo sentido, D’Ambrosio (2005) orienta que a Etnomatemática propõe que na organização de uma proposta educacional é fundamental compreender a relação existente entre a realidade dos sujeitos, o conhecimento matemático adquirido ao longo da vida e o conhecimento necessário para atender as suas necessidades imediatas e futuras. Esse entendimento foi percebido nas declarações obtidas dos participantes que revelaram a existência de uma lacuna entre o ensino pretendido e o que é desenvolvido nas escolas indígenas.

Conforme declarado pelo $\mathrm{T} 1$, o conhecimento matemático que circula na comunidade é suficiente para as atividades básicas do cotidiano, entretanto quando incumbidos de tarefas que exigem conhecimentos matemáticos e conceitos mais elaborados enfrentam dificuldades. Ele afirmou:

Eu acredito que para resolver as questões do dia a dia o conhecimento é suficiente, agora tem outras questões que requer um conhecimento a mais. A gente tem algumas dificuldades quanto a números, cálculo, que são base até mesmo para a gente trabalhar as questões do território populacional, a porcentagem de indígenas de cada região, a questão fundiária, hectares e outras questões também (T1). 
A declaração do T1 evidencia a importância de que a educação escolar esteja atenta as necessidades atuais, atendendo as necessidades básicas desenvolvidas na própria comunidade e outras que são decorrentes do contexto da sociedade contemporânea, o que exige novos conhecimentos.

Entre as necessidades básicas que utilizam o conhecimento matemático tradicional, a construção das moradias (Figura 3) resiste aos costumes da sociedade não indígena.

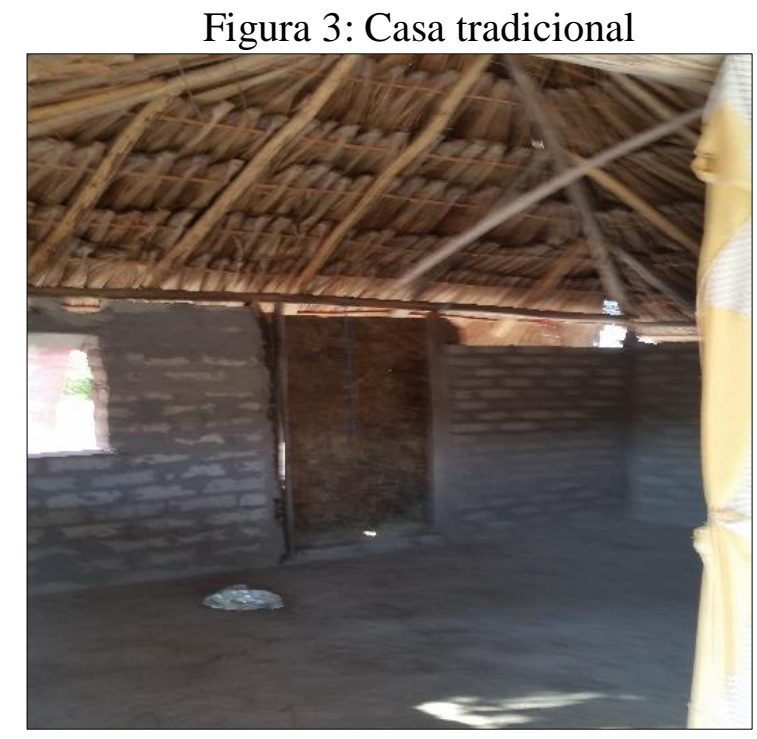

Fonte: a pesquisa.

Para construir a casa apresentada na Figura 3, é necessário o emprego de diversos conhecimentos tradicionais, tais como, produzir os adobes, retirar as madeiras e folhas de buriti que serão usadas na cobertura no período adequado para garantir maior durabilidade, tudo em quantidades adequadas evitando desperdícios e trabalho desnecessário.

As paredes das casas são construídas com adobes, que são tijolos feitos de forma artesanal na própria comunidade, utilizando barro e água e que não passam pelo processo de queima. A fabricação exige conhecimentos específicos e quem não os possui precisa pagar pelo serviço de produção, que varia de acordo com o tamanho do adobe, que não tem medida padronizada. Assim, a quantidade usada por metro quadrado na construção também varia, entretanto fazem os cálculos por aproximação, como declarado por um morador quando perguntado sobre essas questões: "depende do tamanho da casa, se ela for de quatro metros de frente por seis metros de comprimento eu tenho uma base que 
também vai depender do tamanho do adobe, se a forma é grande ou pequena, vai depender. Se eu for dividir a casa por dentro, aí vai ter paredes, usa mais adobe” (Sr. J.).

Na declaração do Sr. J. há evidências de que o saber tradicional é válido nas suas atividades cotidianas, no entanto se mostra frágil ou não é suficiente quando a perspectiva é de um planejamento para as quantidades necessárias de materiais para a construção das casas. Se no contexto da comunidade as aproximações realizadas, considerando as informações dadas pelo Sr. J., podem se mostrar eficazes, atingindo o propósito de produzir material suficiente para a construção de uma moradia, em possíveis relações como, por exemplo, o comércio em Boa Vista, talvez não fossem o suficiente para que um membro da comunidade realizasse uma compra com o conhecimento necessário para que a mesma fosse a mais adequada.

Conforme afirmação dada pelo T1, os povos indígenas têm buscado construir um currículo que contemple os seus conhecimentos e, segundo ele "A gente tem trabalhado com isso, no conhecimento prá formação do currículo, prá voltar-se ao conhecimento tradicional. Incluir dentro do currículo o conhecimento tradicional[...]”. Sobre a questão G1 argumentou que "Primeiramente, o aluno tem que saber da cultura do seu povo, a sua cultura, a sua língua mas depois ele tem que ter acesso a outros conhecimentos". Nesta mesma linha de pensamento P1 declara que,

[...] o aluno também traz os conhecimentos dele, ele aprende as vezes com o pai, com a mãe, então ele traz conhecimento para dentro da escola também para compartilhar juntamente com o professor. É importante sim que a escola valorize esse conhecimento. É muito importante porque a nossa cultura, na verdade, ela não pode perecer né. Por mais que o aluno está estudando na escola, digamos assim, numa escola que aprende sobre outra cultura, a outra cultura na verdade não é nossa, mas mesmo assim nós temos que valorizar a nossa cultura que é da caça, da pesca e também de outras coisas né. E também aprender da outra cultura, a gente precisa dela. Tá todo mundo vivendo do mesmo jeito".

A relevância do conhecimento matemático é indiscutível e, de acordo com Skovsmose (2007), esse conhecimento está presente em todos os lugares, de maneira que a Educação Matemática ocorre em todos os espaços, formais e não formais, envolvendo pessoas e grupos diferenciados e aplicada a contextos específicos. Nessa mesma perspectiva, Cantoral (2013) afirma que toda forma de saber tem seu valor, entretanto, via de regra, os saberes construídos socialmente ao adentrarem nos sistemas escolares adquirem as características de conteúdo ou unidades temáticas perdendo o seu significado.

Assim, constata-se que a Matemática está presente no dia a dia da comunidade, bem como presente no contexto escolar, porém, essas "duas" matemáticas podem estar de tal forma dissociadas que, talvez, o que é desenvolvido na escola não potencialize o que já é de domínio e conhecimento dos membros da comunidade de modo a, de alguma 
forma, ser percebida como útil. Já a escola, se centrada em um conhecimento matemático formal, dispensando o que emerge dos saberes e práticas manifestados nas comunidades corre o risco de desenvolver um conhecimento desprovido de significado.

Assim, no contexto escolar, D’Ambrosio (2009) avalia que o professor ainda permanece agindo como transmissor do conhecimento, tratando o ensino como treinamento para resolver problemas já explorados, mas o mundo atual exige novas atitudes e posturas para atuar mutuamente com o estudante, motivando-o a agir com criticidade diante das situações que se depara. Nessa perspectiva, a educação está sendo desafiada a preparar os estudantes de hoje para atuar no mundo amanhã, ou seja, o conhecimento adquirido deverá atender as demandas de um mundo que passa por transformações imediatas e essa visão deve estar presente, também, na Educação Escolar Indígena.

A percepção da existência de novas demandas na educação escolar é manifestada pelo R1 ao considerar que, mesmo morando em uma comunidade indígena, na zona rural, é preciso que o estudante saiba como manusear o computador, tenha contato com as tecnologias digitais, pois frequentemente vão para a cidade. Conforme relatou o R1, a escola precisa estar atenta para questões mais amplas, e não somente a listagem de conteúdos:

Na Matemática é preciso dinamizar um pouco a questão do estudo. Problematizar. Não ir só no tradicional também. Não só em números, mas tipo assim, também na realidade do povo indígena e não só na teoria. $\mathrm{O}$ aluno precisa aprender sobre as tecnologias porque chega lá na cidade, aqui não, mas chegam lá acessa um site, alguma coisa na internet, ele tem que estar interagindo assim prá não ser enganado (R1).

Por sua vez, os estudantes manifestaram as suas opiniões afirmando que "a Matemática é a base de tudo, mas é ensinada só fazendo o aluno repetir. Isso não atrai” (E10). Afirmaram, também, acreditar que seria mais fácil aprender se as aulas abordassem assuntos conhecidos e presentes no seu dia a dia, conforme relatado pelos estudantes E9 e E11 respectivamente: "na comunidade tem muitas coisas que a gente pode estudar"; "gostaria que a gente estudasse mais na brincadeira, fazendo saia, brinco, darruana, aí eu acho que os alunos iam ficar mais interessados”.

Porém, o R8 destacou a necessidade de que ambos os conhecimentos mantenham diálogo, ao declarar que "Eu acho que tem que conhecer das duas culturas, tem que interagir prá quando saírem prá fazer faculdade não sentirem dificuldade lá fora. O estudo é muito importante porque é através dele que lá frente pode ser um médico, um advogado e passar a defender o seu povo (R8)".

Constatou-se, ainda, que os estudantes veem a escola como uma ponte que dá acesso a outras culturas e, no caminho de volta, faz o reencontro com a sua cultura. Sobre 
a questão o E14 observou que "é importante conhecer outras culturas, mas é importante também aceitar a nossa cultura" e, o E5 declarou que "é preciso saber da cultura do branco mas é preciso conhecer que somos indígenas. Somos diferentes, mas precisamos viver igual".

Desse modo, é possível perceber que para os estudantes indígenas, o acesso aos conhecimentos ditos universais favorece o enfrentamento das questões do mundo atual e o trânsito na sociedade não indígena, possibilitando o ingresso na Universidade e no mercado de trabalho, em empregos na própria comunidade ou na cidade, sendo que o conhecimento adquirido na escola contribui, também, para a atuação dos jovens nos assuntos de interesse próprio e da sua comunidade.

Sobre a educação escolar Skovsmose, Scandiuzzi, Valero \& Alrø avaliam que a mesma pode ser um meio de ascensão tanto profissional quanto social e os "[...] estudantes que pertencem a grupos sociais desfavoráveis e marginalizados têm que lidar com a desoladora questão de quem eles são e quem podem tornar-se [...] ", de modo que suas percepções sobre as suas possibilidades de vida "[...] são cheias de experiências conflitantes, realidades, sonhos e esperanças para o futuro. Tudo isso pode gerar, neles, motivos para se voltarem à educação" (2012, p. 234).

Concordando-se com os autores, entende-se que não faz sentido o ensino da Matemática como uma disciplina formatada para unificar os estudantes, insistindo em um modelo de educação que a concebe a partir de uma visão estratificadora. Pondera-se que é importante pensar na aquisição do conhecimento matemático também como uma estratégia para o desenvolvimento da autonomia e para a conquista de objetivos traçados, particulares ou coletivos.

Considera-se, assim, que a Educação Escolar Indígena deve estar pautada na valorização e no fortalecimento dos aspectos socioculturais do povo envolvido, sendo relevante construir um currículo de Matemática tomando como referência os saberes e as práticas produzidas na comunidade, entendendo que "as tradições que perpassam as gerações, é um caminho que pode contribuir para o aprendizado dos estudantes [...]" (Voltolini \& Kaiber, 2017, p. 637).

Nesse contexto, a investigação realizada buscou identificar elementos os quais possam servir como indicadores para a construção desse currículo encontrando, na realização de projetos de aprendizagem uma proposta pedagógica viável para agregar os saberes que circulam nas comunidades. Como exemplo, destacam-se o uso dos adobes nas construções das moradias, a organização da roça para o plantio e a retirada da quantidade suficiente das madeiras e das folhas de buriti usadas na cobertura das casas reforçando, conforme ressaltam Voltolini \& Kaiber (2017), que os conhecimentos escolares ganham significado quando podem ser colocados em uso. 


\section{Considerações finais}

O estudo apresentado faz parte de um trabalho ainda não concluído, porém já permite perceber que para os povos indígenas o conhecimento adquirido e praticado no seu ambiente contribui para que as suas necessidades básicas sejam assistidas. Entretanto, é necessário que novos conhecimentos sejam adquiridos para que possam resolver questões mais amplas, principalmente nas relações estabelecidas com a sociedade não indígena.

Dessa compreensão, avalia-se que a E.E.I Adolfo Ramiro Levi desempenha um papel fundamental nesse processo, pois os participantes acreditam que valorização dos saberes e práticas culturais e a aquisição de conhecimentos formais podem ser articulados e agregados ao currículo instituído na escola, tornando-se, assim, a base para uma educação, de fato, específica e diferenciada.

Considerando que a sobrevivência da cultura e da tradição de um povo depende da sua valorização e preservação, e que o mundo contemporâneo exige que os conhecimentos sejam constantemente atualizados, pondera-se que a Etnomatemática, a Educação Matemática Crítica e a Socioepistemologia apresentam aspectos teóricos que podem orientar a organização do currículo de Matemática na Educação Escolar Indígena. Pondera-se que tais referenciais norteiam os caminhos que levam ao reconhecimento do ambiente sociocultural do estudante, valorizando seus saberes e fazeres, reconhecendo as suas especificidades, primando para que os conhecimentos adquiridos promovam a autonomia e a conquista de novas oportunidades para a ascensão social.

Nessa perspectiva, o entendimento sobre um currículo específico e diferenciado para a Educação Escolar Indígena nos anos finais do Ensino Fundamental das escolas estaduais indígenas de Roraima expõe a necessidade de novas abordagens para o ensino da Matemática, o que se busca com o desenvolvimento dos mencionados projetos de aprendizagem subsidiados pelas teorias abordadas.

\section{Referências}

André, M. E. D. A. (2004). Etnografia da prática escolar. Campinas: Papirus.

Araújo, J. L. (2007). Educação matemática crítica na formação de pós-graduandos em educação matemática, In. J. Loiola de Araújo. (Org.) Educação matemática crítica: reflexões e diálogos (pp. 25-38). Belo Horizonte: Argumentun.

Brasil (1988). Constituição. Brasília: Senado Federal. 
Brasil (2005). Ministério da Educação e Cultura. Ministério da Educação, Secretaria de Educação Continuada, Alfabetização e Diversidade. Referencial Curricular Nacional para as Escolas Indígenas. MEC/SECADI. Brasília.

Brasil (2015). Câmara dos Deputados. Edições Câmara. Lei de Diretrizes e Bases da Educação Nacional. Lei n. 9.394/96. Brasilia.

Cantoral, R. (2013). Teoria Socioepistemológica de la Matemática Educativa. Estudios sobre construcción social del conocimiento. DME - Cinvestav: Gedisa editorial.

Cantoral, R. (2016). Educación alternativa: matemáticas y práctica social. Presentación, (pp. 7-18). R. Cantoral (Coord.), Instituto de Investigaciones sobre la Universidad y la Educación (IISUE). Universidad Nacional Autónoma de México, XXXVIII, n. especial. Retirado em 13 de agosto, 2017, de: https://pylvar2017.wixsite.com/pylvar/articulos-pulicados

Cantoral, R., Montiel, G. \& Reyes-Gasperini, D. (2015). El programa socioepistemológico de investigación em matemática educativa: El caso de latinoamérica. Editorial. In: Revista latino-americana de educación em matemática educativa - RELIME, 18(1), 5-17. Disponível em: http://www.clame.org.mx/relime.htm

Cantoral, R., Reyes-Gasperini, D. \& Montiel, G. (2014). Socioepistemologia, matemáticas y realidad. Revista Latinoamericana de Etnomatemática, 7 (3), 91-116. Disponível em: http://www.revista.etnomatematica.org/index.php/RevLatEm/issue/view/17

Cervantes Reyes, Ó. A. \& Reyes-Gasperini, D. (2016). La construcción social de un lenguaje simbólico desde las prácticas. Perfiles Educativos (pp. 67-86), XXXVIII, n. especial. IISUE: UNAM. Retirado em 19 de setembro, 2017, de: http://www.iisue.unam.mx/perfiles/articulo/2016-e-la-construccion-social-de-unlenguaje-simbolico-desde-las-practicas.pdf

D’Ambrosio, U. (2001). Prefácio. In: A. MONTEIRO \& G. POMPEU JR. A matemática e os temas transversais (pp. 7-10). São Paulo: Moderna.

D’Ambrosio, U. (2005). Etnomatemática - elo entre as tradições e a modernidade. Belo Horizonte: Autêntica.

D’Ambrosio, U. (2009). Educação Matemática: da Teoria à Prática. Campinas: Papirus.

D’Ambrosio, U. (2011). Educação para uma sociedade em transição. Natal: EDUFRN.

Freire, J. R. B. (2004). Trajetória de muitas perdas e poucos ganhos. In: Educação escolar indígena em Terra Brasilis: tempo de novo descobrimento, (pp. 11-31). Rio de Janeiro: IBASE. Retirado em 28 de setembro, 2017. Disponível em: http://old.socialwatch.org/es/informeImpreso/pdfs/IBASE-Educacao-EscolarIndigena-Em-Terra-Brasilis.pdf

Luciano, G. S.. (2006). O Índio Brasileiro: o que você precisa saber sobre os povos indígenas no Brasil de hoje. Série Vias dos Saberes, 1. MEC/SECAD: Brasília. 
DOI: https://doi.org/ 10.20396/zet.v26il.8650861

Retirado em 11 de novembro, 2015. Disponível em: http://laced.etc.br/site/Trilhas/livros/arquivos/ColET12_Vias01WEB.pdf

Monteiro, A. \& Pompeu Junior, G. (2001). A matemática e os temas transversais. São Paulo: Moderna.

Skovsmose, O. (2007). Educação crítica: incerteza, matemática, responsabilidade. Trad. de M. A. V. Bicudo. São Paulo: Cortez.

Skovsmose, O. (2011). Educação matemática crítica: a questão da democracia. Trad. de A. Lins, J. de L. Araújo. Campinas: Papirus.

Skovsmose, O., Scandiuzzi, P. P., Valero, P., \& Alrø, H. (2012). A aprendizagem Matemática em uma posição de fronteira: foregrounds e intencionalidade de estudantes de uma favela brasileira. Bolema, 26 (42A), 231-260. Disponível em: http://www.scielo.br/pdf/bolema/v26n42a/11.pdf

Voltolini, L. (2011). Conhecimentos matemáticos: um contexto em transição na comunidade indígena Serra da Moça. Dissertação de Mestrado em Ensino de Ciências e Matemática. Canoas: Universidade Luterana do Brasil. Canoas, 2011.

Voltolini, L. \& Kaiber, C. T. (2015). A Etnomatemática como perspectiva pedagógica: uma proposta para atender as demandas na E.E.I. Índio Ajuricaba. Anais do XIV CIAEM-ACME (pp. 13-22). Chiapas, México: Educación Matemática en las Américas 2015, vol. 5. Etnomatemática y Sociología. Retirado em 23 de outubro, 2017, de: http://ciaem-redumate.org/memorias-ciaem/xiv/pdf/Vol5Etnom.pdf

Voltolini, L. \& Kaiber, C. T. (2017). Educação Escolar Indígena e Educação Matemática: um estudo na Comunidade Indígena Serra da Moça. Acta Scientiae, 19 (4), 619-639). Disponível em: http://www.periodicos.ulbra.br/index.php/acta/article/view/3355/2528

Recebido em: 30/09/2017

Aprovado para publicação em: 03/04/2018 